\title{
The role of workload and job satisfaction in general health of industrial workers in Gonabad, Iran, in 2015
}

\author{
Beheshti MH, MSc ${ }^{1}$, Hajizadeh R, MSc ${ }^{2 *}$, Khodaparast E, MSc ${ }^{3}$, Shojaei R, BS ${ }^{4}$, Ranjbar E, BS ${ }^{5}$ \\ 1- Faculty Member, Dept. of Occupational Health, Faculty of Health, Gonabad University of Medical Sciences, Gonabad, \\ Iran. 2- PhD Student, Qom University of Medical Sciences, Qom, Iran. 3- Faculty Member, Dept. of Safety, School of \\ Health Safety Environment, Shahid Beheshti University of Medical Science, Tehran, Iran.4- BSc in Industrial Ceramics, \\ Dept. of Health and Safety, Gonabad Company of Taghdis Porcelain, Gonabad, Iran 5- BSc in Occupational Health, Dept. of \\ Health and Safety, Gonabad Company of Taghdis Porcelain, Gonabad, Iran.
}

Abstract

Received: June 2015, Accepted: August 2015

Background: The lack of satisfaction and balance between the workload and abilities and limitations of individuals in various occupations may influence their general health. The aim of this study was to determine the effect of workload and job satisfaction on the general health of industrial workers.

Materials and Methods: This was a cross-sectional and correlational study on 215 workers of a Chinese manufacturing industry in Khorasan Razavi Province, Iran. Data were collected using the Job Satisfaction Questionnaire, NASA Task Load Index (NASA-TLX), and General Health Questionnaire (GHQ). Data analysis was conducted using SPSS software and through computing the Pearson and Spearman's correlation coefficients and step-wise regression.

Results: The general health score of $60 \%$ of women and $45.1 \%$ of men was greater than the cut-off score of 21 as a determinant of health and non-health. In addition, $80.6 \%$ of men and $74.8 \%$ of women had social problems. The overall workload of $26.53 \%$ of men and $23.7 \%$ of women was over 70 (high workload) and the workload of $69.38 \%$ of men and $69.23 \%$ of women was between 40 and 70 (intermediate). Based on these result, the average job satisfaction score is moderate and $60.2 \%$ of men and women have shown moderate satisfaction. The result of correlation test showed no statistically significant correlation between workload and job satisfaction and general health $(\mathrm{P}>$ 0.05). Moreover, no significant relationship was observed between job satisfaction and general health $(\mathrm{P}>0.05)$.

Conclusions: The results of the study suggest that authorities should pay special attention to the general health of industrial workers, especially with respect to social disorders. In addition, given the direct relationship between some subscales of workload and job satisfaction, and general health, further studies are needed to identify these factors.

Keywords: Mental Health, Public Health, Workload, Job Satisfaction, Worker, Industrial

\section{Introduction}

The lack of balance between the workload and abilities and limitations of individuals in various occupations may influence their general health. The protection and promotion of health in occupational environments is a major task of managers and planners. In this regard, ergonomics is one of most important sciences that can significantly help managers and planners achieve health-related objectives.
From an ergonomic point of view, the most critical factor involved in occupational accidents and injuries is the inconsistency between the workload and abilities and limitations of individuals (1). Physical and mental health of individuals may be affected by various work factors (2). Studies have

\footnotetext{
* Corresponding author: Roohalah Hajizadeh, Qom University of Medical Sciences, Qom, Iran. Email: roohalahhajizade@gmail.com
} 
shown that occupational stress is associated with minor psychiatric disorders. Issues such as the rate of absenteeism, abuse of substance and drugs, apathy and loss of motivation are higher in workers than others, and therefore, affect their occupational satisfaction and mental health (3). Dissatisfaction, work overload, lack of time, and physical stress are factors that directly affect the mental health of the individual (4). Workload is a set of job requirements, the effort to perform the work, and efficiency and performance of individuals. Excessive workload leads to increasing of mental and physical stress and job dissatisfaction and may be a threat to public health workers. Individuals with low job satisfaction have low mental health (5). Occupational satisfaction is an established feeling that every person has about their job. According to Herzberg's two-factor theory, job satisfaction can be divided into motivational and preservative factors (6). Satisfaction is a concept of high importance in medical care and has come to the attention of scholars since 1950. Job satisfaction has a close relationship with social stability and social stability can develope communities; therefore, in order to achieve sustainable development, job satisfaction must be taken into consideration (7). Job satisfaction is one of the most important factors in Increase human performance. In addition, it causes correct functioning, increase in efficiency, and reduction in injuries (8). Employees who are dissatisfied with their work are more susceptible to physical and psychological symptoms, and absenteeism (9). The World Health Organization (WHO) reported in 2001 that approximately 45 million people worldwide suffer from mental disorders and 1 in 4 people experience some signs of mental disorders in different stages of their life (10). The studies suggest that high stress arising from work and occupational stresses are associated with mild mental disorders (11). Problems such as excessive absenteeism, substance and drugs abuse, apathy at work, and low motivation are greater in stressed people, and affect their job satisfaction and mental health (11).

The study by Mohammadi et al. showed that the prevalence of psychiatric disorders in Mazandaran province, Iran, is $21.52 \%$; the prevalence in women and men was $30.12 \%$ and $12.33 \%$, respectively (12). Anxiety disorders and mood disorders, with incidence rate of $10.17 \%$ and $5.48 \%$, respectively, were the most common psychiatric disorders in the province (12). In this study, $14.58 \%$ of the subjects had at least 1 psychiatric disorder (12). Geykee et al., in a study conducted in Finland, found that workers who have lower job satisfaction, experience worse accidents or incidents compared to others (13). Stress and job dissatisfaction are mental and emotional responses and occur when there is a lack of balance between work demands and ability (11). Occupational stress is the major cause of mental disorder, particularly depression (14). Long-term stress results in job burnout (15). In developed countries, psychiatric disorders are largely identified through screening questionnaires and clinical interviews. Planning for provision of essential mental health services to individuals requires knowledge of stress and tension in the workplace the most important factor of which is increased mental load. In Iran, unlike the existence of policies for identifying and controlling physical and chemical factors in the working environment, there is no regular policy for monitoring, identifying, and controlling ergonomic factors, especially mental factors. Moreover, risk factors of high mental and physical workload and psychological disorders have not come to the attention of authorities. Furthermore there are a limited number of studies in this field. In this study, workload, job satisfaction, and general health and the relationship among them were investigated in workers in a Chinese manufacturing industry in Khorasan Razavi Province, Iran. 


\section{Materials and Methods}

This was a cross-sectional descriptivecorrelational study on 215 workers of a Chinese manufacturing industry in Khorasan Razavi province. The participants were studied using the census method. This study was conducted in summer 2015. The data collection tools consisted of 3 questionnaires. The NASA-Task Load Index (NASA-TLX) was used to evaluate workload, Job Satisfaction Questionnaire to evaluate occupational stress, and General Health Questionnaire (GHQ-28) to examine the general health of the study population.

Moreover, another questionnaire was used to collect demographic data of the employees. To observe research ethics, necessary information about the goals of the study and the confidentiality of the study were given to the participants, and their written consents were obtained before completing the questionnaires.

\section{NASA-TLX Questionnaire}

This questionnaire consists of 2 parts, the first part investigating overall workload and the second part determining the importance of each subscale of workload in the view of the respondent.

Part one: Evaluation of the relative importance of each subscale of workload. The subscales examined in this study include mental demand, physical demand, temporal demand, effort, performance, frustration.

Mental demand refers to the extent of psychological activities (e.g. reflection, decision-making, calculation, and recollection of past events); whether a task is simple, difficult, complex, or convenient.

Physical demand refers to the amount of physical activity required (e.g. pushing, pulling, and physical movement); whether the task is easy or demanding, requires quick reaction, or is physically laborious.

Temporal demand refers to the pressure exerted as a result of time restriction of the task and whether it should be performed quickly or slowly.

The subscale of effort refers to the extent of hard work (in terms of intellectual and physical requirements) required to deliver the work at a desirable level.

The subscale of performance refers to the degree of obtaining the intended goals (occupational objectives) by an individual or their satisfaction with these goals.

The subscale of frustration refers to the level of frustration, dissatisfaction, annoyance, and stress a person is experiencing (it is the opposite of hopefulness, peace, and satisfaction).

Part two: Determining the level of importance of each subscale of workload (in a scale of 0100). The respondent's give scores from o to 100 for each subscale of workload in accordance with their personal condition.

Using the analytic hierarchy process, the importance of each dimension was compared to other dimensions. This one-to-one analysis was part of the questionnaire in which the respondents were required to answer the questions based on their conditions and criteria specified in the definition of each in the first part of the questionnaire. The analysis was performed on the basis of choices made by the respondents. In other words, the parameters were determined in the questionnaire and choices/comparisons were made by the respondents. The weight of each dimension was obtained from the total workload of each respondent. Then, the total workload of individuals was calculated as a number between 0 and 100 by multiplying the weight of each workload subscale (a value between 0 and 1) by the specified level (a number between 0 and 100).

\section{General Health Questionnaire (GHQ-28)}

This psychological questionnaire is the most well-known screening tool in psychiatry, and was designed by Goldberg and Hillier (16). The 28-item questionnaire consists of 4 scales each containing 7 items that evaluate physical symptoms, anxiety, impaired social functioning, and depression. The intensity of these scales is evaluated on a scale ranging from extremely low to extremely high with each item obtaining a score of 0-3. In this 
study, which was carried out in Iran, a cut-off score of 21 was obtained. In the study by Sharifi et al., the correlation between the data obtained from the implementation of the Symptom Checklist-90-Revised (SCL90-R) and GHQ-28 on 244 respondents was 0.87 (17).

\section{Job Satisfaction Questionnaire}

This questionnaire was developed by Dalt et al. in 1996 based on Herzberg's two-factor theory.

Each phrase was scored using a 7-point scale. The respondents were asked to read the terms carefully and determine the degree of their agreement. The score of each phrase ranged from 1 to 7,1 and 7 , respectively, representing the highest and lowest degree of agreement. This questionnaire contains 36 phrases about job dissatisfaction and 36 phrases about personal satisfaction. Each phrase contains motivational and health factors. In general, the questionnaire consists of two parts.

The results of Job Satisfaction Questionnaire, based on total score, were divided into 3 groups. Scores of 25 or lower show weak job satisfaction, scores between 26 to 74 show moderate job satisfaction, and scores higher than 75 show desirable job satisfaction.
A referral letter was obtained from Gonabad University of Medical Sciences and presented to the company. Then, the questionnaires were distributed among employees. They were assured that participation in this study was voluntary, and the information collected will be anonymous and confidential. Data were analyzed simultaneously using SPSS software (version 15, SPSS Inc., Chicago, IL, USA) and Spearman's correlation coefficient, t-test, and multiple regressions.

\section{Results}

In the present study, 215 workers (124 men and 91 women) with an average age of $29.88 \pm$ 5.07 years and minimum and maximum age of 20 and 45 years were studied. The average work experience of employees was 5.04 years with a minimum and maximum of 1 and 16 years, respectively. Amongst the participants, 55 were single and 160 were married.

Based on the results, mean score of general health was $24.84 \pm 11.36$. The minimum and maximum public health score of participants was 3 and 57, respectively. Table 1 displays the results of general health of workers in terms of sex.

Table 1: Description of each subscale of workload in industrial workers

\begin{tabular}{|c|c|c|c|c|c|c|c|c|c|c|c|c|c|c|}
\hline & \multicolumn{2}{|c|}{$\begin{array}{l}\text { Mental } \\
\text { demand }\end{array}$} & \multicolumn{2}{|c|}{$\begin{array}{l}\text { Physical } \\
\text { demand }\end{array}$} & \multicolumn{2}{|c|}{$\begin{array}{c}\text { Temporal } \\
\text { demand }\end{array}$} & \multicolumn{2}{|c|}{ Effort } & \multicolumn{2}{|c|}{$\begin{array}{c}\text { Performanc } \\
\text { e }\end{array}$} & \multicolumn{2}{|c|}{ Frustration } & \multicolumn{2}{|c|}{$\begin{array}{c}\text { Total } \\
\text { workload }\end{array}$} \\
\hline & W & M & W & M & W & M & W & M & W & M & W & M & W & M \\
\hline Mean & 59.7 & 67.8 & 62.6 & 72.3 & 69.2 & 65.9 & 67.3 & 70.2 & 37.8 & 41.8 & 40.1 & 43.4 & 56.3 & 60.2 \\
\hline \pm & \pm & \pm & \pm & \pm & \pm & \pm & \pm & \pm & \pm & \pm & \pm & \pm & \pm & \pm \\
\hline $\mathrm{SD}$ & 4.03 & 3.78 & 4.44 & 2.71 & 3.6 & 2.54 & 4.01 & 2.47 & 3.71 & 3.00 & 4.20 & 3.06 & 1.82 & 1.48 \\
\hline Minimum & 0 & 0 & 0 & 0 & 0 & 0 & 0 & 0 & 0 & 0 & 0 & 0 & 0 & 0 \\
\hline Maximum & 100 & 100 & 100 & 100 & 100 & 100 & 100 & 100 & 100 & 100 & 100 & 100 & 100 & 100 \\
\hline
\end{tabular}

M: Men; W: Women; SD: Standard deviation

Generally, $60 \%$ of women's and $45.1 \%$ of men's health scores were over the cut-off score of 21 (18). Moreover, the scores of physical symptoms in $50 \%$ of men and $56.92 \%$ of women, and sleep disorder in $64.61 \%$ of women and $50 \%$ men were over cut-off score. The score of social problems in $80.6 \%$ of men and $74.8 \%$ of women, and depression score in 
$32.30 \%$ of women and $14.2 \%$ of men were also over the cut-off score (6). According to the results of table 2, mean scores of general health in men and women were $23 \pm 1.07$ and $27.57 \pm 1.5$, respectively. Furthermore, the average score of 3 somatic symptoms, anxiety, sleep disorders, and social disorders, in women and men are more than the cut-off score (6).
Results of independent t-test showed a significant relationship between gender and general health $(\mathrm{P}=0.012)$ and lower general health in women compared to men. A significant association does not exist between marital status and public health $(\mathrm{P}=0.354)$. Workload data of the study population is presented in table 1 .

Table 2: Results of general health of industrial workers

\begin{tabular}{cccccccccccc}
\hline & \multicolumn{2}{c}{$\begin{array}{c}\text { Physical } \\
\text { symptoms }\end{array}$} & \multicolumn{2}{c}{$\begin{array}{c}\text { Anxiety and } \\
\text { sleep disorders }\end{array}$} & \multicolumn{2}{c}{$\begin{array}{c}\text { Social } \\
\text { disorders }\end{array}$} & Depression & \multicolumn{2}{c}{ General health } \\
\cline { 2 - 13 } & Women & Men & Women & Men & Women & Men & Women & Men & Women & Men \\
\hline Mean & 6.85 & 5.35 & 7.69 & 6.35 & 8.38 & 8.72 & 4.48 & 2.4 & 27.57 & 23 \\
\pm & \pm & \pm & \pm & \pm & \pm & \pm & \pm & \pm & \pm & \pm \\
SD & 0.48 & 0.31 & 0.62 & 0.45 & 0.44 & 0.45 & 0.58 & 0.36 & 1.5 & 1.07 \\
\hline Minimum & 1 & 1 & 0 & 0 & 2 & 0 & 0 & 0 & 8 & 3 \\
\hline Maximum & 18 & 14 & 18 & 21 & 19 & 21 & 17 & 16 & 57 & 48 \\
\hline
\end{tabular}

SD: Standard deviation

Based on the results of this study, workload scores of about $26.53 \%$ of men and $23.07 \%$ of women were over 70 . The workload scores of about $69.38 \%$ of men and $69.23 \%$ of women were between 40 and 70 . Data on workload variables using NASA-TLX show that the average workload score of men was 56.3 and of women was 60.2. Among the different dimensions of the NASA-TLX, physical load and level of effort (scores: 72.3 and 70.2, respectively) in men and time restriction and level of effort (score: 69.2 and 67.3, respectively) in women had the highest scores. Among the various aspects of workload in both men and women "performance" and "feel discouraged" had the lowest score. Independent t-test results showed no significant association between gender and workload $(\mathrm{P}=0.092)$. In addition, there was no significant relationship between marital status and workload $(\mathrm{P}=0.0384)$.

Based on our results, mean score of job satisfaction according to gender in the research community for men and women were 132.83 and 133.26 , respectively. With regard to the gradation range of 36-108 (no job satisfaction), 109-171 (average satisfaction), and 171-216 (complete satisfaction), 26.15\% of men and $22.46 \%$ of women were dissatisfied with their jobs. Furthermore, $60.2 \%$ of men and $60 \%$ of women showed average satisfaction, and $13.84 \%$ of women and $17.34 \%$ of men were satisfied with their jobs. Independent t-test results showed no significant relationship between gender and job satisfaction $(\mathrm{P}=0.945)$ and marital status and job satisfaction, $(P=0.259)$. Spearman's correlation coefficient showed no significant relationship $(\mathrm{P}>0.05)$ between age and workload, and job satisfaction and general health. It also showed that there was no significant relationship between experience and workload, and job satisfaction and general health $(\mathrm{P}>0.050)$. The relationship between workload and job satisfaction and general health showed that Spearman's correlation coefficient between workload with job satisfaction was 0.016 and between workload and general health was -0.037 .

The Pearson correlation test showed a significant correlation between workload, and job satisfaction and public health $(\mathrm{P}>0.050)$. 
The results of statistical analysis to determine the relationship between job satisfaction and general health showed that Spearman's correlation coefficient between job satisfaction and general health was 0.151 . The Pearson correlation coefficient showed that there was no significant relationship between job satisfaction and general health $(\mathrm{P}>0.050)$.

\section{Discussion}

According to the results, the public health score of a significant number of workers $(60 \%$ of women and $45.1 \%$ of men) was over the cut-off score (18). In addition, the determinants of health and non-health and general health in women were lower than men. Amongst the different subscales of general health, social disorders had the highest score. In fact, $80.6 \%$ of men and $74.8 \%$ of women had social disorders. The social aspect of health can be seen as the most complex and yet controversial aspect of the health system. The WHO introduces social health as one of the key components of health, but due to lack of a valid instrument, this concept is still the subject of political and social debates (4).

Several studies have substantiated the effect of the work environment and work requirements on general health of individuals (4). Zare et al. in their study on workers of the Industrial and Mining Company, Gol Gohar, Sirjan, Iran, showed that $29.4 \%$ of workers had psychological disorders (19). They also found that $53.1 \%$ of the workers suffered from poor sleep quality and $57.5 \%$ from depression, and $10.2 \%$ complained of physical symptoms (19). In addition, the study by Halvani et al. at the mine of Kushk, Iran, showed that $25.8 \%$ and $24.5 \%$ of workers were not in suitable condition in terms of public health and physical health, respectively (20). They also found that $28.9 \%, 43.6 \%$, and $7.5 \%$ of workers suffered from anxiety, impaired social functioning, and depressive conditions, respectively. Furthermore, more than $21 \%$ of them were not satisfied with their job and employer (20).
Comparison of the results with other studies in this field showed a high prevalence of social problems in miners and industrial workers.

Based on the results of this study, the total workload score of $26.53 \%$ of men and $23.7 \%$ of women was over 70 (high workload), and of $69.38 \%$ of men and $69.23 \%$ of women was between 40 and 70 (intermediate). Nevertheless, in general, the mean workload of men and women is at an average level. Physical load and level of effort (score: 72.3 and 70.2, respectively) in men, and time restriction and level of effort (score: 69.2 and 67.3, respectively in women had the highest scores among the different dimensions of NASA-TLX.

The Pearson correlation coefficient showed that there was no significant relationship between workload, and job satisfaction and general health. Khandan et al. in a study on the relationship between workload and job satisfaction, also found no significant correlation between the total score of job satisfaction and workload (9). They observed a positive relationship between job satisfaction and performance, and a negative correlation between frustration and job satisfaction (9). The relationship between occupational stress and many cardiovascular risk factors including diabetes (21), body mass index (22), hypertension, hyperlipidemia, overweight, smoking, alcohol consumption and its severity, triglyceride and high and low density lipoprotein levels (23-24), and heart rhythm and metabolic syndrome (24) have also been investigated. However, the findings in this field are incongruous $(23,25,26)$.

According to the results, mean score of job satisfaction in the survey was at an average level and $60.2 \%$ of men and women showed average satisfaction. The Pearson correlation showed that there is no significant relationship between job satisfaction and general health.

The study of Navidian et al. showed a significant relationship between the intensity of stress factors and general health of nurses (4). That is, an increase in intensity of stress factors was associated with deteriorated 
general health (negative correlation coefficient) (4).

Most relevant studies in this field confirm the relationship between the intensity of job stress experienced by individuals and their mental health status $(4,27,28,29)$. However, given the different job values and perceived characteristics of work environments, motivation, and attitude, there is a high chance of obtaining different results in Iran. Of course, this inconsistency is not far from expectation, since job satisfaction and workload, as psychological phenomena, are affected by a range of factors, including jobinduced stress and workload. There are many risk factors that can intensify job satisfaction and workload. Nevertheless, it should be noted that satisfaction and workload are to a large extent generated by risk factors which influence individuals. In addition to environmental factors and stressors, intrapersonal factors, such as cognitive, attitudinal, emotional, and personal components, are also involved in increasing stress and workload.

Navidian et al. found that measures such as reducing workload through recruiting more employees, utilizing the services of people interested and experienced in these fields, providing a comfortable and appropriate physical environment, dedicating a break time for relaxation after critical situations, and alleviating the workload can help reduce the above stressors (4). By identifying stressor factors in these jobs and attempting to reduce them through adopting reforms in organizational, physical, and caring structures, we can reduce the stress and promote the physical and psychological health and job satisfaction of employees, and consequently, increase their life quality.

It is recommended that, in recruiting individuals for these jobs, some psychological tests, such as personality characteristics, be administered to the applicants at the outset of their reception and regular examinations at centers specialized in occupational medicine services be offered to them. Moreover, regular training programs and medical and psychological education should be provided for these people.

The present study had a number of limitations. First, the research data are based on selfmonitoring, which may be biased. Moreover, this research is limited to workers of a Chinese manufacturing industry in Khorasan Razavi province. Thus, caution should be practiced in generalizing its results to other groups.

Furthermore, since it was a correlational study, it is difficult to discover causal relationship. Thus, to identify the causes of job satisfaction, workload, and general health, experimental research or causal studies are required.

\section{Conclusions}

Given the results of this study and the body of research in this field, it can be concluded that there is a significant relationship between some basic subscales of workload, and job satisfaction and general health. We recommend extensive research to identify environmental stress and job dissatisfaction factors affecting public health and to control solutions in order to eliminate or reduce ergonomic risk factors.

\section{Acknowledgement}

The present study has been registered as a research project by the Vice Chancellor for Research at Gonabab University of Medical Sciences. The authors would like to express their appreciation for Gonabad University of Medical Sciences and health and safety of the studied Chinese manufacturing company.

\section{Conflict of interest: None declared}

\section{References}

1. Paterson JL, Dorrian J, Pincombe J, Grech C, Dawson D. Mood change and perception of workload in Australian midwives. Ind Health 2010; 48(4):381-9.

2. Behrouzian F, Khajeddin N, Hodaei F, Zamani $\mathrm{N}$. The relationship of job satisfaction and coping mechanism with general health, among 
private industrial's staff. Jundishapur Scientific Medical Journal 2009; 8(3):345-53.

3. Sahraian A, Fazelzadeh A, Mehdizadeh AR, Toobaee SH. Burnout in hospital nurses: a comparison of internal, surgery, psychiatry and burns wards. Int Nurs Rev 2008; 55(1):62-7.

4. Navidian A, Masoudi GhR, Mousavi SS. Work-related Stress and the General Health of Nursing Staffs in Zahedans' Hospitals Emergency Wards(2004). Journal of Kermanshah University of Medical Sciences 2007; 9(3):17-26.

5. Lin PC, Chen $\mathrm{CH}$, Pan SM, Chen YM, Pan $\mathrm{CH}$, Hung $\mathrm{HC}$, et al. The association between rotating shift work and increased occupational stress in nurses. J Occup Health 2015; (0).

6. Shaghaghi M, Abbasi R, Abbasi R, Borzooei M. Effect of Job Satisfaction and Stress on Pursuing the Conflict Management Strategies by Librarians of Iran Public Libraries Foundation. Research to information Science and public libraries 2011; 17(1):53-70.

7. Hojat M, Mohebi J, Nazari V, Charkh-Andaz M. Personnel and patients satisfaction as a measure of service quality measurement. Iran Journal of Nursing 2010;23(65):73-82.

8. Khandan M, Roshan-zamir S, Maghsoudipour M. Survey of Workload and Job Satisfaction relationship in a Productive Company. Iran Occupational Health 2012; 9(1):30-6.

9. Behrozyan F, Khajedin N, Hadaee F, Zamani $\mathrm{N}$. The relationship of job satisfaction and coping mechanism with general health, among private industrial's staff. Private Sector Industrial Journal of Medicine Science 2009; 8(3):345-53.

10. Ahmadvand A, Sepehrmanesh Z, Ghoreyshi F, Assarian F, Moosavi GA, Saee R, et al. Prevalence of Mental Disorders in General Population of Kashan City. Iranian Journal of Epidemiology 2010; 6(2):16-24.

11. Peter R, Siegrist J. Psychosocial work environment and the risk of coronary heart disease. Int Arch Occup Environ Health 2000; 73(Suppl):S41-5.

12. Mohammadi MR, Bagheri-Yazdi SA, Rahgozar M, Mesgarpoor B, Bab-Alhavaeji A, Lotfi A, et al. An epidemiological study of psychiatric disorders in Hamadan province, 2001. Scientific Journal of Hamedan University of Medical Sciences and Health Services 2004; 11(3):28-36.

13. Gyekye SA, Salminen S. Making sense of industrial accidents: The role of job satisfaction. Journal of Social Sciences 2006; 2(4):127-34.

14. Kawasaki S, Nishimura Y, Takizawa R, Koike S, Kinoshita A, Satomura Y, et al. Using social epidemiology and neuroscience to explore the relationship between job stress and frontotemporal cortex activity among workers. Soc Neurosci 2015; 10(3):1-13.

15. Embriaco N, Papazian L, Kentish-Barnes N, Pochard F, Azoulay E. Burnout syndrome among critical care healthcare workers. Curr Opin Crit Care 2007; 13(5):482-8.

16. Goldberg DP, Hillier VF. A scaled version of the General Health Questionnaire. Psychol Med 1979; 9(1):139-45.

17. Yaghoubi N, Nasr M, Shah-Mohammadi D. Prevalence of mental disorders in Someesara (Gilan) rural and urban areas. [PhD Thesis]. Iran University of medical sciences; 1995.

18. Khandan M, Roshanzamir S, Maghsoudipour M. Survey of Workload and Job Satisfaction relationship in a Productive Company. Iran Occupational Health 2012; 9(1):30-6.

19. Zare S, Shabani N, Babaei Heydarabadi A, Asghari M, Aminizadeh R, Nazemorroaya V, et al. Investigation of the relationship between general health and workers' sleep quality and work incidence in Gole Gohar Mineral Industries Co., Sirjan. journal of ilam university of medical sciences 2013; 21(2):11219.

20. Halvani G, Morowatisharifabad M, Baghianimoghadam M. Determining the general health status of workers of Kuushk mine. koomesh 2007; 8(4):261-8.

21. Agardh EE, Ahlbom A, Andersson T, Efendic S, Grill V, Hallqvist J, et al. Work stress and low sense of coherence is associated with type 2 diabetes in middle-aged Swedish women. Diabetes Care 2003; 26(3):719-24.

22. Kouvonen A, Kivimäki M, Cox SJ, Cox T, Vahtera J. Relationship between work stress and body mass index among 45,810 female and male employees. Psychosom Med 2005; 67(4):577-83.

23. Niedhammer I, Goldberg M, Leclerc A, David S, Bugel I, Landre MF. Psychosocial work environment and cardiovascular risk factors in an occupational cohort in France. J Epidemiol Community Health 1998; 52(2):93-100.

24. Kang MG, Koh SB, Cha BS, Park JK, Woo JM, Chang SJ. Association between job stress on heart rate variability and metabolic syndrome in shipyard male workers. Yonsei Med J 2004; 45(5):838-46.

25. Bosma H, Peter R, Siegrist J, Marmot M. Two alternative job stress models and the risk of coronary heart disease. Am J Public Health 1998; 88(1):68-74.

26. Peter R, Alfredsson L, Hammar N, Siegrist J, Theorell T, Westerholm P. High effort, low reward, and cardiovascular risk factors in 
employed Swedish men and women: baseline results from the WOLF Study. J Epidemiol Community Health 1998; 52(9):540-7.

27. Arnold E, Boggs K. Interpersonal Relationships: Professional Communication Skills for Nurses. 7th ed. Amsterdam: Elsevier; 2015. Chapter 16, Empowerment Oriented Communication Strategies to Reduce Stress; $p$ 309.
28. Laposa JM, Alden LE, Fullerton LM. Work stress and posttraumatic stress disorder in ED nurses/personnel. J Emerg Nurs 2003; 29(1):23-8.

29. Spector PE, Zhou ZE, Che XX. Nurse exposure to physical and nonphysical violence, bullying, and sexual harassment: A quantitative review. Int J Nurs Stud 2014; 51(1):72-84. 